\title{
Оценка благосостояния с позиции устойчивого человеческого развития: возможности международных индексов
}

\author{
Нестерова О.А. ', Пожарницкая О.В. ${ }^{1}$ \\ ${ }^{1}$ Томский государственный университет систем управления и радиоэлектроники, Томск, Россия
}

\begin{abstract}
АННОТАЦИЯ:
В представленной статье рассматривается возможность использования международных индексов для оценки благосостояния на основе выявления экономической, экологической и социальной составляющих с позиции устойчивого человеческого развития. Проанализированы шестнадцать международных индексов, выступающих в качестве альтернативных мер оценки уровня благосостояния. Проведенный авторами сравнительный анализ индексов основывался на таких ключевых требованиях, как строгая связь с благосостоянием; выбор значимых индикаторов; достоверность и доступность данных; возможность межстранового сопоставления. Все индексы сгруппированы в три блока: основные/целевые показатели, используемые для оценки благосостояния; субъективные показатели благосостояния; показатели устойчивого развития человека. Обосновывается необходимость измерения благосостояния с учетом не только выявления перспективы основных потребностей общества, но и перспективы возможностей, принимая во внимание данные разного информационного пространства, не упуская красоту поиска человеко-экологических связей внутри каждого измерения.
\end{abstract}

КЛючЕВЫЕ словА: благосостояние, качество жизни, счастье, индикатор, индекс.

Assessing well-being from the perspective of sustainable human development: the potential of international indices

Nesterova 0.A. ${ }^{1}$, Pozharnitskaya O.V. ${ }^{1}$

${ }^{1}$ Tomsk State University of Control Systems and Radioelectronics, Russia

\section{Введение}

2 а последние тридцать лет появилось множество различных альтер-

нативных показателей измерения человеческого развития, в том числе учитывающих проблемы устойчивости и межпоколенческие аспекты развития человека.

Широкий спектр новых индикаторов альтернативного развития человечества распространился, начиная от всеобъемлющих показателей, таких как «Индекс социального прогресса» М. Портера, до более субъективных альтернатив, таких, как, например, индекс счастья. В связи с этим возникает ряд вопросов: чем, в первую очередь, необходимо руководствоваться при выборе показателей, каковы основные 
критерии, должны ли мы отказаться от простых показателей и использовать более сложные индексы?

Учитывая богатство и разнообразие показателей, использующихся для оценки человеческого развития, качества жизни, прогресса и устойчивости системы человечества, и невозможность их полного исследования в одной статье, основное внимание авторов будет уделено рассмотрению важнейших видов международных индексов/ индикаторов, используемых для оценки благосостояния.

В целом в исследованиях по благосостоянию обычно проводится различие между субъективными и объективными измерениями благосостояния. На протяжении длительного времени в научных статьях критикуется эквивалентность валового внутреннего продукта (ВВП) и благосостояния. Акцент смещается к более широкой трактовке благосостояния, включающей процветание, хорошую жизнь или альтернативные представления о процветании, в сторону, где меньшее внимания уделяется материальному уровню жизни.

В докладе концептуальной рабочей группы под названием «Оценка экосистем на пороге тысячелетия» представлено много формулировок и дефиниций благосостояния людей. Безусловно, согласимся с авторами доклада в том, что благосостояние включает базовое материальное обеспечение для нормальной жизни, ощущение свободы,

\begin{abstract}
:
The article considers the possibility of using international indices to assess well-being, based on the identification of economic, environmental and social components, from the perspective of sustainable human development. Sixteen international indices serving as alternative measures of assessment of the level of well-being are analyzed. The comparative analysis of indices carried out by the authors is based on such key requirements as a strict relationship with well-being, the choice of significant indicators, the reliability and availability of data, the possibility of cross-country comparison. All indices are grouped into three blocks: core/target indicators used to measure well-being; subjective indicators of well-being; indicators of sustainable human development. The article substantiates the need to measure wellbeing, taking into account not only the prospects of the basic needs of society, but also the prospects of opportunities, taking into account the data of different information space, without missing the beauty of the search for human-environmental relations within each dimension.
\end{abstract}

KEYWORDS: welfare, quality of life, happiness, indicator, index.

JEL Classification: 130, 131, 139

Received: 03.08.2018 / Published: 30.09.2018

(c) Author(s) / Publication: CREATIVE ECONOMY Publishers

For correspondence: Nesterova O.A. (PavelBeriylayandex.ru)

\title{
CITATION:
}

Nesterova O.A., Pozharnitskaya O.V. (2018) Otsenka blagosostoyaniya s pozitsii ustoychivogo chelovecheskogo razvitiya: vozmozhnosti mezhdunarodnyh indeksov [Assessing well-being from the perspective of sustainable human development: the potential of international indices]. Voprosy innovatsionnoy ekonomiki. 8. (3). - 335-348. doi: 10.18334/vinec.8.3.39338 
здоровье, личную безопасность и нормальные социальные отношения. Все вместе они обеспечивают условия для социального, психологического и духовного удовлетворения. В докладе отмечается, что иногда делается различие между детерминантами или средствами для достижения благосостояния и его составными элементами, конечной целью которых является благосостояние [10] (Alkamo Dzh. i dr., 2005).

В рамках данной статьи благосостояние людей будет рассматриваться, фиксируя внимание на устойчивом развитии общества в современных условиях глобализации. Кроме этого, не вдаваясь в этимологию слова «благосостояния» и в особенности подходов различных теорий и концепций благосостояния, будет принята тождественность понятий «благосостояния» и «качества жизни».

В связи с многомерностью понятия «благосостояния» возникло огромное количество показателей, в той или иной мере использующихся для его оценки. В данной статье будут рассмотрены 16 индексов/индикаторов ${ }^{1}$ и определена их значимость для оценки устойчивого развития общества с позиции роста благосостояния: ВBП (GDP); Экологически адаптированный чистый внутренний продукт (EDP); Индекс скорректированных чистых накоплений («истинных сбережений» Всемирного банка) (NAS); Чистое экономическое благосостояние (NNW); Индекс экономического благополучия (IEWB); Индикатор подлинного прогресса (GPI); Индекс человеческого развития (HDI); Индекс социального прогресса (SPI); Индекс качества жизни (EIU); Валовое национальное счастье (GNH); Международный индекс счастья (HPI); Индекс лучшей жизни (BLI); Индекс процветания (LPI); Индекс живой планеты (LPI); Экологический след (ЕF); Индекс экологической эффективности (ЕРI).

В этой статье мы сосредоточим внимание на анализе индексов с позиции всесторонней оценки экономических, экологических и социальных (в том числе институциональных) условий, влияющих на благосостояние людей.

\section{Что создает благо?}

Информационной базой в данном исследовании выступили данные разных международных организаций, таких как ООН (в рамках ПРОООН United Nations

${ }^{1}$ В дальнейшем мы будем использовать термин «индекс», опуская различия между индексами и индикаторами.

\section{ОБ АВTOPAX:}

Нестерова Оксана Анатольевна, доцент кафедры экономики, кандидат экономических наук (PavelBeriy囚 yandex.rul

Пожарницкая Ольга Вячеславовна, доцент кафедры экономики, кандидат экономических наук, доцент (povatpu.ru )

\section{ЦИТИРОВАТЬ СТАТЬЮ:}

Нестерова О.А., Пожарницкая О.В. Оценка благосостояния с позиции устойчивого человеческого развития: возможности международных индексов // Вопросы инновационной экономики. - 2018. - Том 8. - № 3. - C. 335-348. doi: 10.18334/vinec.8.3.39338 
Таблица 1

Перечень основных компонент, используемых для оценки благосостояния населения в разрезе экономической, экологической и социальной составляющих

\begin{tabular}{|c|c|c|}
\hline Экономическая составляющая & Экологическая составляющая & Социальная составляющая \\
\hline $\begin{array}{l}\text { - величина валового вну- } \\
\text { треннего продукта на душу } \\
\text { населения; } \\
\text { - паритет покупательной спо- } \\
\text { собности; } \\
\text { - валовые внутренние сбере- } \\
\text { жения; } \\
\text { - индивидуальные потреби- } \\
\text { тельские расходы; } \\
\text { - суммарные инвестиции в } \\
\text { капитал; } \\
\text { - расходы на товары длитель- } \\
\text { ного пользования и др. }\end{array}$ & $\begin{array}{l}\text { - цена загрязнения воды и } \\
\text { воздуха; } \\
\text { - истощение невозобновляе- } \\
\text { мых ресурсов; } \\
\text { - долгосрочный экологиче- } \\
\text { ский ущерб; } \\
\text { - разрушение озонового слоя; } \\
\text { - уменьшение лесного покро- } \\
\text { ва и др. }\end{array}$ & $\begin{array}{l}\text { - ожидаемая продолжитель- } \\
\text { ность жизни; } \\
\text { - уровень грамотности насе- } \\
\text { ления; } \\
\text { - стоимость домашнего труда; } \\
\text { - цена преступности, разво- } \\
\text { дов, безработицы; } \\
\text { - стоимость дорожно-транс- } \\
\text { портных происшествий; } \\
\text { - средний индекс политиче- } \\
\text { ской и гражданской свободы } \\
\text { и др. }\end{array}$ \\
\hline
\end{tabular}

Источник: составлено авторами на основе изученных индексов

Development Program), Всемирный банк, Международная организация труда, комитет содействия развитию Организации экономического сотрудничества и развития; Всемирная организация здравоохранения, ЮНЕСКО; исследовательские университеты; региональные комиссии, занимающиеся изучением этого вопроса и др.

Все шестнадцать индексов/индикаторов рассматриваются с позиции экономической, экологической и социальной составляющих, являющихся основой устойчивого развития ${ }^{2}$ В таблице 1 представлены показатели, характеризующие обозначенные составляющие и их компоненты.

Выбор индексов, тем или иным образом позволяющих дать оценку благосостояния населения, основывался на ключевых требованиях:

- строгая связь с благосостоянием;

- выбор значимых индикаторов (с позиции объективного и субъективного подходов к измерению уровня благосостояния);

- достоверность и доступность (измеримость) данных для количественной оценки в более длительных временных периодах;

- возможность межстранового сопоставления;

- возможность использования индексов для определения социально-экономической политики государства.

В качестве второго критерия классификации основные индексы сгруппированы в три блока, а именно:

\footnotetext{
2 Так, по мнению С.Н. Бобылева, чтобы развитие могло считаться устойчивым, оно должно осуществляться с учетом достижения экономического роста, но при обеспечении его сбалансированности с потребностями общества по улучшению качества жизни и предотвращению деградации окружающей среды [1] (Bobylev, 2007).
} 
1) основные/целевые показатели, используемые для оценки благосостояния;

2) субъективные показатели благосостояния;

3) показатели устойчивого развития человека.

В таблице 2 представлена краткая характеристика шестнадцати индексов, которые широко используются в дискуссиях по измерению благосостояния населения.

\section{Основные/целевые показатели для измерения благосостояния}

Одним из первых и обобщающих показателей, охарактеризовавших благосостояние населения как меру необходимых ресурсов для полноценной жизни, принято считать валовой внутренний продукт (Gross Domestic Product). Однако, как отмечают большинство исследователей в области благосостояния населения, данный макроэкономический показатель не пригоден для его оценки. Для устранения различных недостатков в расчете ВВП и включения неучтенных факторов создается большое количество альтернатив этому показателю.

Так, в 1993 году статистическим отделом Секретариата ООН была предложена Система эколого-экономического учета (System for Integrated Environmental and Economic Accounting), позволяющая скорректировать ВВП под воздействием экологического фактора в национальных статистиках. Результатом коррекции ВВП на основе экологического воздействия является такой показатель, как экологически адаптированный чистый внутренний продукт (Environmentally adjusted net domestic product). Данная система не лишена недостатков, возникает сложность перерасчета экологических данных в стоимостные, также возникают трудности при международном сравнении, однако методические основы «зеленых» счетов продолжают активно развиваться.

Нельзя не упомянуть концепцию, воплощенную в восьми Целях развития тысячелетия (ЦРТ), включающую систему целевых показателей по оценке развития человеческого потенциала.

В научной литературе можно встретить различные взгляды на ЦРТ, в том числе и критические, в отношении того как она была создана и институализирована, а также критику, связанную с ограниченностью дезагрегированных многомерных показателей, их фрагментацией, приводящей к сложности создания концептуальной основы развития.

Конечно, и агрегированные составные показатели также приводят к возникновению целого ряда вопросов, касающихся весов и процесса выбора измерений.

У. Нордхаус и Дж. Тобин в 1972 г. предложили учитывать трансформацию благосостояния общества под влиянием факторов, не отображенных в ВВП, с помощью макроэкономического показателя чистого экономического благосостояния (Net National Welfare). При его исчислении во внимание принимались стоимость нерыночной деятельности, производство общественных благ, оценка досуга, негативное влияние отрицательных факторов экономического роста [11]. Однако единой методологии для его расчета нет. 


\begin{tabular}{|c|c|c|c|c|c|c|c|c|c|c|c|}
\hline \multirow{14}{*}{ 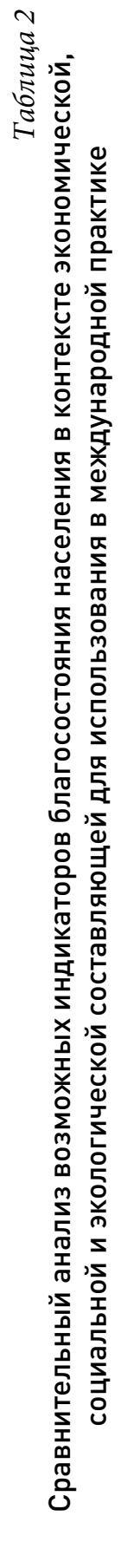 } & \multicolumn{2}{|c|}{ 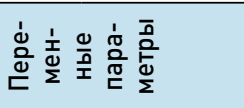 } & - & $m$ & $m$ & $m$ & $\checkmark$ & $\stackrel{\sim}{\sim}$ & $\checkmark$ & $\simeq$ & $a$ \\
\hline & \multicolumn{2}{|l|}{ 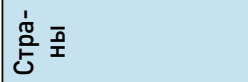 } & $\stackrel{\cup}{\cup}$ & 함 & 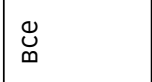 & $: \ll$ & $\vdots$ & เి & 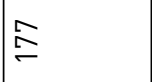 & 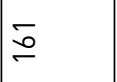 & $\Xi$ \\
\hline & \multicolumn{2}{|c|}{ 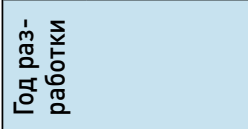 } & $\begin{array}{l}\dot{L} \\
\stackrel{ \pm}{2} \\
\text { a }\end{array}$ & 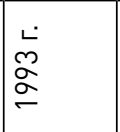 & ㄴ. & 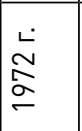 & $\begin{array}{l}\check{L} \\
\infty \\
\sigma \\
\sigma\end{array}$ & 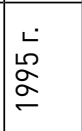 & 追 & 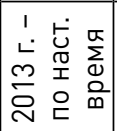 & 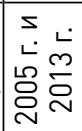 \\
\hline & \multicolumn{2}{|c|}{ 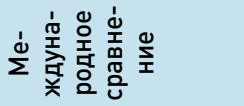 } & $\oplus$ & $\otimes$ & $\oplus$ & $\otimes$ & $\theta$ & $\theta$ & $\oplus$ & $\oplus$ & $\oplus$ \\
\hline & \multirow{3}{*}{ 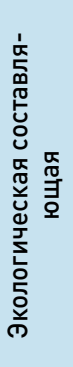 } & 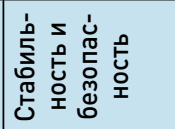 & $\otimes$ & $\otimes$ & $\otimes$ & $\otimes$ & $\oplus$ & $\oplus$ & $\otimes$ & $\oplus$ & $\oplus$ \\
\hline & & 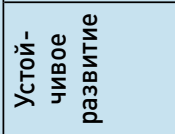 & $\otimes$ & $\theta$ & $\oplus$ & $\theta$ & $\oplus$ & $\oplus$ & $\theta$ & $\oplus$ & $\otimes$ \\
\hline & & 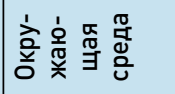 & $\otimes$ & $\oplus$ & $\oplus$ & $\oplus$ & $\oplus$ & $\oplus$ & $\otimes$ & $\oplus$ & $\otimes$ \\
\hline & \multirow{5}{*}{ 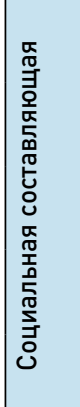 } & 高。 & $\otimes$ & $\otimes$ & $\otimes$ & $\stackrel{\sim}{\oplus}$ & $\oplus$ & $\oplus$ & $\oplus$ & $\oplus$ & $\oplus$ \\
\hline & & 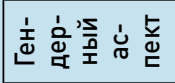 & $\otimes$ & $\otimes$ & $\otimes$ & $\theta$ & $\otimes$ & $\otimes$ & $\stackrel{\circ}{\oplus}$ & $\otimes$ & $\oplus$ \\
\hline & & 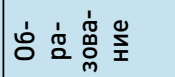 & $\otimes$ & $\otimes$ & $\oslash$ & $\otimes$ & $\otimes$ & $\oplus$ & $\oplus$ & $\oplus$ & $\otimes$ \\
\hline & & 嵩主 & $\otimes$ & $\otimes$ & $\otimes$ & せ & $\oplus$ & $\oplus$ & $\oplus$ & $\oplus$ & $\oplus$ \\
\hline & & 동 & $\otimes$ & $\otimes$ & $\otimes$ & せ & $\oplus$ & $\oplus$ & $\otimes$ & $\otimes$ & $\oplus$ \\
\hline & \multicolumn{2}{|c|}{ 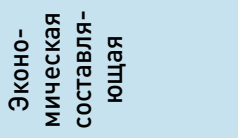 } & $\oplus$ & $\oplus$ & $\oplus$ & $\oplus$ & $\oplus$ & $\oplus$ & $\oplus$ & $\otimes$ & $\oplus$ \\
\hline & \multicolumn{2}{|l|}{ 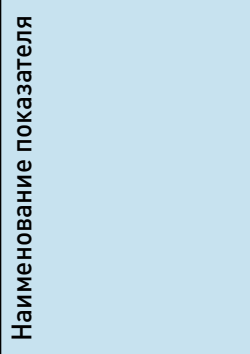 } & 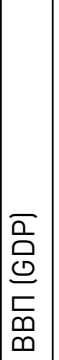 & 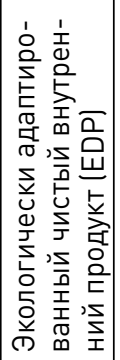 & 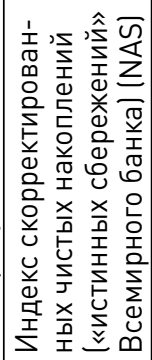 & 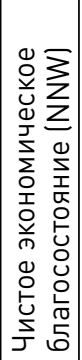 & 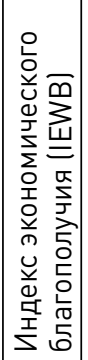 & 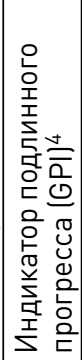 & 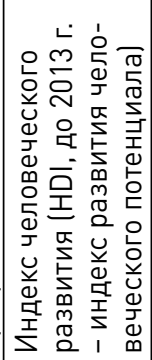 & 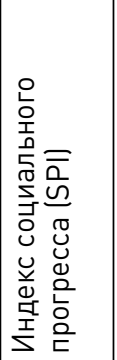 & 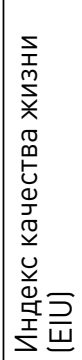 \\
\hline
\end{tabular}




\begin{tabular}{|c|c|c|c|c|c|c|c|}
\hline$\sigma$ & $\checkmark$ & 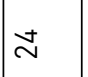 & ळ & $\cong$ & 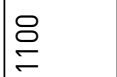 & 0 & $\stackrel{0}{\circ}$ \\
\hline$\vdots$ & $\vdots$ & $\stackrel{\infty}{m}$ & $\underset{\Im}{\Im}$ & 亗 & 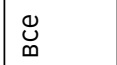 & $\begin{array}{l}\stackrel{\Xi}{凶} \\
\text { | }\end{array}$ & $\stackrel{\infty}{\infty}$ \\
\hline 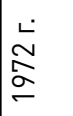 & $\begin{array}{l}\text { L } \\
\text { ○े } \\
\text { مे }\end{array}$ & 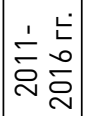 & $\begin{array}{ll}1 & 5 \\
0 \\
0 \\
0\end{array}$ & 送 & 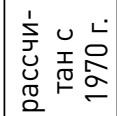 & 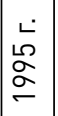 & $\begin{array}{l}\text { L. } \\
\text { ○े } \\
\text { مे }\end{array}$ \\
\hline$\theta$ & $\oplus$ & $\oplus$ & $\oplus$ & $\oplus$ & $\oplus$ & $\oplus$ & $\oplus$ \\
\hline$\oplus$ & $\oplus$ & $\oplus$ & $\oplus$ & $\oplus$ & $\oplus$ & $\oplus$ & $\oplus$ \\
\hline$\oplus$ & $\theta$ & $\oplus$ & $\oplus$ & $\theta$ & $\theta$ & $\theta$ & $\theta$ \\
\hline$\oplus$ & $\oplus$ & $\oplus$ & $\oplus$ & $\otimes$ & $\oplus$ & $\oplus$ & $\oplus$ \\
\hline$\oplus$ & $\stackrel{\infty}{\oplus}$ & $\oplus$ & $\oplus$ & $\oplus$ & $\oplus$ & $\oplus$ & $\oplus$ \\
\hline$\otimes$ & $\otimes$ & $\otimes$ & $\otimes$ & $\otimes$ & $\otimes$ & $\otimes$ & $\otimes$ \\
\hline$\oplus$ & $\otimes$ & $\oplus$ & $\oplus$ & $\otimes$ & $\otimes$ & $\otimes$ & $\otimes$ \\
\hline$\oplus$ & $\oplus$ & $\oplus$ & $\oplus$ & $\theta$ & $\otimes$ & $\otimes$ & $\oplus$ \\
\hline$\theta$ & $\otimes$ & $\oplus$ & $\oplus$ & $\theta$ & $\otimes$ & $\otimes$ & $\otimes$ \\
\hline$\oplus$ & $\otimes$ & $\oplus$ & $\oplus$ & $\otimes$ & $\otimes$ & $\otimes$ & $\otimes$ \\
\hline 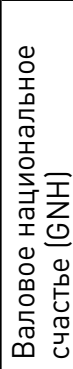 & 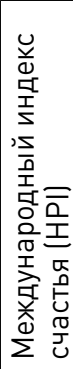 & 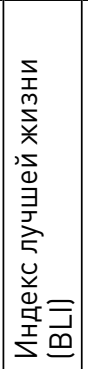 & 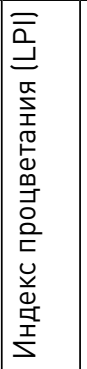 & 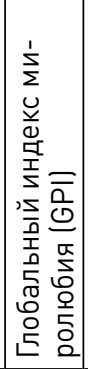 & 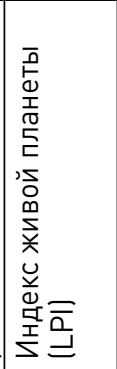 & 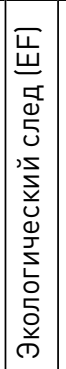 & 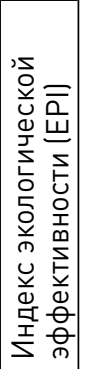 \\
\hline
\end{tabular}
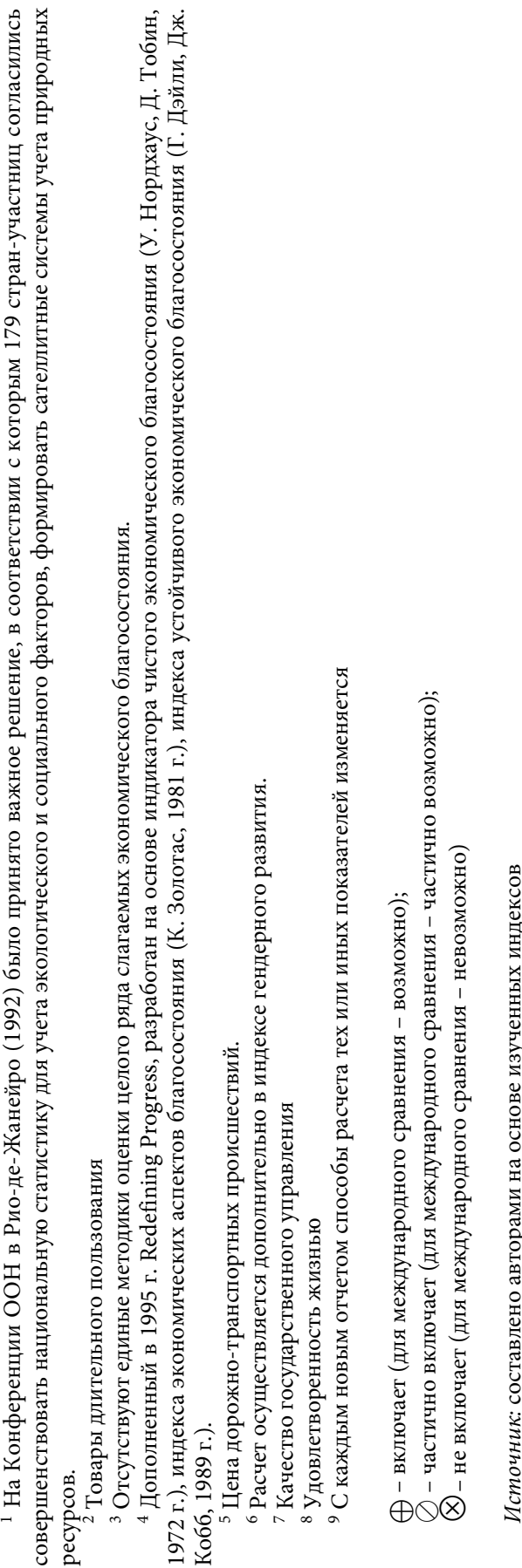
Наиболее часто используемым агрегированным показателем, позволяющим дать оценку благосостояния общества, а также самой известной альтернативой ВВП, стал Индекс человеческого развития (Human Development Index). Расчет данного показателя для разных государств осуществляется через индикаторы уровня жизни, грамотности, образованности и долголетия и позволяет проводить межстрановые сравнения. Однако в индексе человеческого развития отсутствует экологическая составляющая.

Индекс социального прогресса (Social Progress Index) является первой всеобъемлющей основой, служащей для измерения достижений стран с точки зрения их социального развития. В индексе выделены три измерения, так же как и в ИЧР, но они более широкие по своему характеру и включают в себя «базовые потребности человека» (питание, вода, жилье и безопасность); «основы благосостояния» (знания, информация, здоровье и устойчивость экосистемы); «возможности» (личная свобода, право выбора, доступ к получению высшего образования). Индекс имеет много привлекательных функций особенно с точки зрения рассмотрения возможностей человека.

Индекс социального прогресса содержит 12 компонентов и 52 отдельных показателя, группируя их в трех измерениях. Расчет индекса охватывает $94 \%$ населения мира (133 страны и 28 стран с частичными данными), хотя это незначительно ниже, чем охват индексом человеческого развития.

Индекс качества жизни (The Quality of Life Index), разработанный компанией Economist Intelligence Unit, увязывает результаты субъективных обследований удовлетворенности жизнью с объективными показателями качества жизни в разных странах. Особенностью данного индекса считается чрезмерная простота в расчетах. Индекс был подсчитан в 2005 и в 2013 годах. При расчете Индекса качества жизни используется девять переменных, однако такая важная составляющая благосостояния общества, как образование, в расчет не включена.

Кроме этого исследователи выделяют Индекс лучшей жизни (Better Life Index) и Индекс процветания (Legatum Prosperity Index).

По методологии организации экономического сотрудничества и развития, Индекс лучшей жизни включает в себя 24 переменных. Данный индекс является интерактивным, то есть необходимо самостоятельно присваивать значимость любому из одиннадцати аспектов благополучия, что изменяет рейтинг стран в соответствии с приоритетом пользователя.

Индекс процветания, разработанный британским аналитическим центром Legatum Institute в 2007 году, включает в себя 89 переменных и отражает не только уровень богатства, но и уровень благосостояния по 8 сферам.

Также существует достаточно большое количество индексов, которые оценивают уровень благосостояния населения с одной из обозначенных нами составляющих. Так, Глобальный индекс миролюбия (Global Peace Index), разработанный учеными международной группы экспертов по миру Института мира совместно с Центром мира и изучения конфликтов Сиднейского университета, характеризует уровень безопасности проживания. 
Рассмотрение самых популярных критических замечаний агрегированных и дезагрегированных показателей может стать хорошей иллюстрацией тех ограничений, с которыми сталкиваются многомерные показатели, но это выходит за рамки нашего исследования.

\section{Субъективные показатели благосостояния}

Значительный интерес представляет собой изучение субъективных индексов, несмотря на то, что многими теоретиками они игнорируются, из-за субъективности взглядов, сложности количественной оценки и др.

Однако изучение детерминантов человеческого счастья стало одной из самых острых тем в экономике за последние десятилетия, причем размер и глубина научных исследований в этом направлении возрастает с экспоненциальной скоростью (так, к примеру, 140 статей в год, опубликованных в 1980 году, увеличиваются до 18000 в 2018 г.).

Как известно, одним из основных катализаторов в литературе о доходе и счастье была оригинальная статья Р. Истерлина (1974 г., обновленная в 1995 г., 2005 г.).

Принимая во внимание, что существует много альтернативных мер, позволяющих субъективно измерить благосостояние/благополучие, предлагаемые в качестве альтернативной меры ВВП и другим экономическим показателям, например, «Всемирный обзор ценностей», предложенный социологом Р. Инглхартом, включающий основополагающие базовые ценности, собранные практически по всему миру, «Индекс удовлетворенности жизнью» (Life satisfaction Index), - комбинированный показатель, предложенный Эдрианом Уайтом и свидетельствующий о наличии сильной корреляции между субъективным благополучием, с одной стороны, и здоровьем, богатством, доступом к базовому образованию - с другой. В наличии Руководство ОЭСР по измерению субъективного благополучия и множество других. Рассмотрим некоторые из них более подробно.

Замена ВВП категорией «валового национального счастья» (Gross National Happiness) впервые была предпринята в Бутане и подразумевала измерение качества жизни в балансе между материальным и духовным. Само это понятие было введено еще в 1972 году королем Бутана Джигме Сингье Вангчуком [9] (Shmatova, Morev, 2015). Бутан является единственной страной, которая приняла валовое национальное счастье вместо ВВП в качестве основного показателя развития.

Международный (всемирный) индекс счастья HPI (Happy Planet Index) разработан в 2006 г. британским исследовательским центром New Economic Foundation при сотрудничестве ряда мировых экспертов. Как отмечают его разработчики, «индекс измеряет устойчивое благосостояние для всех. Это говорит нам о том, что хорошего страны делают для достижения долгой, счастливой, устойчивой жизни» [4]. Индекс включает в себя четыре элемента (самочувствие, ожидаемая продолжительность жизни, неравенство и экологический след) и отражает эффективность использования экологических ресурсов, чтобы вести долгую, счастливую жизнь. 
Особого внимания заслуживает всемирный доклад о счастье, в котором отмечается, что счастье признается надлежащей мерой социального прогресса и целью государственной политики. Первый Всемирный доклад о счастье был опубликован в 2012 года, после этого внесен ряд изменений с целью повышения благосостояния. В докладе подчеркивается, что различия в восприятии счастья в большей степени объясняются для процветающих стран различиями психического, физического здоровья и личных отношений, для бедных стран наиболее важны различия в доходах.

Если обратиться к данным Всемирного доклада о счастье 2016 г. [13] и данным Доклада о человеческом развитии 2016 г.[3] $]^{3}$, то можно увидеть значительные расхождения между рейтингами некоторых стран. Например, Япония, которая занимает 17 место по ИЧР, по рейтингу счастья занимает 53-е место, тогда как Коста-Рика, которая является 66 страной в рейтинге ИЧР, занимает 14 место в рейтинге счастья. Аналогичным образом выглядит ситуация в отношении Южной Кореи, которая занимает 18-е место в рейтинге ИЧР и 58-е в рейтинге счастья, а Бразилия - 79-е по ИЧР и 17-е место в рейтинге счастья. Это свидетельствует о том, что существуют важные различия между Восточной Азией и Латинской Америкой, заключающиеся в том, как люди оценивают и ценят свое благополучие.

Налицо противоречия и различия между объективными и субъективными оценками, что отражает сложность процесса человеческого развития и обосновывает необходимость поиска новых эталонов с учетом различных аспектов жизни в разных странах.

\section{Показатели устойчивого человеческого развития}

Несмотря на популярность индикаторов устойчивости в 1990-х годах, а также увеличение интереса в настоящее время, в научных сценариях доминируют три основных набора показателей, а именно: 1) композитные индексы; 2) показатели состояния окружающей среды; 3) показатели устойчивости экологической среды («зеленые» национальные счета).

Эти индексы отчетливо отражают теоретический спор, связанный с концептуальной неточностью и непониманием того, что точно показатели окружающей среды измеряют - состояние экологической среды или возможности «позволить удовлетворить потребности нынешнего времени, не ставя под угрозу способность будущих поколений удовлетворять свои потребности» [7].

К композитным индексам можно отнести Всемирный индекс счастья НРI (Нарру Planet Index), каковой, как было указано выше, призван оспорить хорошо зарекомендовавшие себя показатели, такие как ВВП и индекс человеческого развития, не учитывающие устойчивое развитие.

\footnotetext{
${ }^{3}$ Данные взяты из докладов 2016 г, в связи с отсутствием данных Доклада о человеческом развитии в более поздней версии
} 
Новым развитием идеи оценки благосостояния населения послужил Индекс устойчивого экономического благосостояния (Index of Sustainable Economic Welfare), рассчитанный Г. Дэйли и Дж. Кобб в 1989 г., включавший экологические аспекты и использование природных ресурсов. В данный индекс ученые включили такие переменные, как стоимость загрязнения воды, воздуха, шумового загрязнения и другие экологические факторы. На основе индекса устойчивого экономического благосостояния некоммерческой организацией Redefining Progress Institute из Сан-Франциско в 1995 году был разработан и стал довольно широко использоваться индикатор подлинного прогресса (Genuine Progress Indicator) ${ }^{4}$, отличающийся способом вычисления коэффициентов независимых переменных. При расчетах данного индекса были корректно учтены многие факторы устойчивого экономического развития.

Процесс экологизации общества, основанный на понимании негативного воздействия экономической активности населения на окружающую среду, привел к активной разработке и использованию для оценки благосостояния населения ряда экологических индексов, например, Индекса живой планеты (Living Planet Index) и др. ${ }^{5}$

Еще одним из самых заметных индексов является Индекс экологической эффективности (Environmental Performance Index), разработанный исследователями Йельского университета и Колумбии (Environmental Performance Index by Yale and Columbia universities). Ориентируясь на состояние окружающей среды, экологической устойчивости, данный индекс рассчитывается на основе 16 показателей, однако методика его расчета постоянно корректируется. Вследствие этого данные несопоставимы и провести анализ, выявить динамику и определить «узкие» места за продолжительный период не представляется возможным.

В 2008 году по инициативе президента Франции Николя Саркози была создана Комиссия по измерению эффективности экономики и социального прогресса (Дж. Стиглиц, А. Сен, Ж. П. Фитусси). Главная ее задача состояла в идентифицировании пределов использования валового внутреннего продукта (ВВП) как показателя, выступающего для оценки экономического развития и социального прогресса.

В докладе, подготовленном этой комиссии (2009), проводится различие между оценкой текущего благосостояния и оценкой устойчивости, говорится о необходимости рассмотрения современного благосостояния как через призму экономических ресурсов, так и через призму неэкономических аспектов жизни людей; на основании этого предлагаются основные рекомендации, направленные на коренное изменение основ государственной статистики во Франции и во всем мире [2, 14] (Stiglitz, Sen, Fitoussil).

Одна из важных рекомендаций Комиссии в отношении измерения благосостояния заключается в разработке показателей благосостояния/качества жизни по каждому из

\footnotetext{
${ }^{4}$ Индекс стал очень популярен в США после публикации знаковой статьи «Если ВВП растет, то почему Америка «падает»?» («If the GDP is up, why is America down?»)

${ }^{5}$ Этот список можно продолжить, используя и другие показатели, разработано более 100 индексов
} 
ее аспектов, которые позволили бы получить исчерпывающую и глобальную оценку неравенства. Национальный институт статистики и экономических исследований (НИСЭИ) разработал объективные показатели качества жизни, которые не ограничиваются чисто материальными или денежными аспектами [12]. Они также учитывают условия труда, степень социальной интеграции, здравоохранение и образование, отсутствие экономической стабильности (например, безработицу) и физической безопасности, что дает, таким образом, глобальное представление о неравенстве [2].

Среди показателей, отражающих состояние окружающей среды, наиболее заметным является Экологический след (Ecological Footprint) Всемирного фонда дикой природы. Ежегодный отчет о живой планете дает информацию о показателях биоемкости и экологического долга. Данный показатель можно использовать для изучения связей, например, между нищетой и качеством окружающей среды и др.

Основная идея этих показателей заключается в том, чтобы дополнить ВВП, который, как известно, не учитывает потери благосостояния из-за ухудшения состояния окружающей среды. В рамках этого направления важным показателем является индекс скорректированных чистых/истинных накоплений/сбережений (Adjusted Net Savings), методологически оформленный специалистами Всемирного банка в 2000 г. Данный индекс характеризует скорость накопления национальных сбережений за вычетом истощения природных ресурсов и урона от загрязнения окружающей среды.

Существуют и другие показатели, которые не предназначены для всеобъемлющей оценки благосостояния, но все же затрагивают конкретные аспекты человеческого развития, это и показатели экономической и политической свободы, показатели условий жизни, индикаторы использования рабочего времени и отдыха, показатели отсутствия безопасности, и др. Они могут быть очень полезны в размышлениях о природе благосостояния, о возможностях, а также о скрытых за ними неравенствах, но многие из них не рассматривались в настоящей статье в связи с небольшим охватом стран.

Таким образом, для поиска индикаторов благосостояния населения, способных лучше отражать как ожидания граждан, так и современные вызовы экономического развития, нами были рассмотрены шестнадцать показателей. Анализ их составляющих и компонент показал, что сочетание экологических, экономических и социальных аспектов наблюдается только в четырех: индикатор подлинного прогресса, индекс человеческого развития, индекс качества жизни, индекс лучшей жизни; и только три из них пригодны для межстранового сравнения.

\section{Заключение}

1. Перечисленные группы индексов иллюстрируют различные нормативные и ценностные категории, используемые для построения показателей, имеющих отношение к развитию человека и благосостоянию.

2. Однако прежде чем делать какие-либо выводы или предложения о том, какие альтернативные индикаторы могли бы выступить в качестве измерителя благососто- 
яния, необходимо подойти к изучению его концептуальных основ, с учетом не только выявления перспективы основных потребностей общества, но и перспективы возможностей, принимая во внимание данные разного информационного пространства, не упуская красоту поиска человеко-экологических связей внутри каждого измерения.

3. Поэтому вопрос о разработке индекса, оценивающего благосостояние общества, учитывающего «экологический след» экономической активности населения в широком смысле, а также включающего экономические и социальные факторы, остается весьма актуальным.

\section{ИСТОЧнИКИ:}

1. Бобылев С.Н. Индикаторы устойчивого развития: региональное измерение. Пособие по региональной экологической политике. - М.: Акрополь, ЦЭПР, 2007. - 60 с.

2. Вопросы для информации: измерение эффективности экономики и социального прогресса. Unstats.un.org. [Электронный ресурс]. URL: https://unstats.un.org/unsd/ statcom/doc11/2011-35-France-R.pdf (дата обращения: 17.05.2018).

3. Доклад о человеческом развитии 2016. Человеческое развитие для всех и каждого. / Пер. с англ. Human Development Report 2015: Human Development for Everyone 2017 г. - М.: Весь Мир, 2017.

4. Официальный сайт Happy Planet Index. [Электронный pecypc]. URL: http:// happyplanetindex.org/about.

5. Павлова И.А., Гуменников И.В., Монастырный Е.А. Международные интегральные индексы как сравнительные методики макроуровня в оценке благополучия пожилого населения // Вестник науки Сибири, 2017. - № 1(24).

6. Степашин С.М., Шахрай С.М., Попова С.М., Яник А.А. Об индикаторах оценки уровня социально-экономического развития и прогресса. Icc.msu.ru. [Электронный pecypc]. URL: http://icc.msu.ru/sites/default/files/Indicators.pdf (дата обращения: 18.06.2018).

7. Устойчивое развитие: Доступный индекс человеческого развития. Unece.org. [Электронный ресурc]. URL: http://www.unece.org/fileadmin/DAM/stats/documents/ ece/ces/ge.15/2013/WP_16_UNDP_D_Ru.pdf (дата обращения: 15.07.2018).

8. Хажеева M.А. Сравнительные методики оценки благосостояния населения на уровне мировой экономики. Интернет-журнал «Науковедение». [Электронный ресурс]. URL: https://naukovedenie.ru/PDF/196EVN613.pdf.

9. Шматова Ю.Е., Морев М.В. Измерение уровня счастья: литературный обзор российских и зарубежных исследований // Экономические и социальные перемены: факты, тенденции, прогноз, 2015. - № 3(39). - doi: 10.15838/esc/2015.3.39.11.

10. Алкамо Дж. и др. Экосистемы и благосостояние людей: рамки оценки // Оценка экосистем на пороге тысячелетия: Доклад концептуальной рабочей группы. США, 2005.

11. ArtexTrade. [Электронный ресурс]. URL: http://www.artextrade.ru/economy/macro/ chistoe-ekonomicheskoe-blagosostoyanie (дата обращения: 10.07.2018). 
12. Insee, Objective Indicator of Quality of Life, report prepared for the ninety-sixth conference of the Directors-General of National Statistical Institutes (DGINS), Sofia, September 2010; INSEE, @ Une mesure de la qualité de vie», France, portrait social, 2010 edition.

13. Helliwell, J., Layard, R., \& Sachs, J. (2016). World Happiness Report 2016, Update (Vol. I). New York: Sustainable Development Solutions Network.

14. Stiglitz Joseph E., Sen Amartya, Fitoussi Jean-Paul. Report by the Commission on the Measurement of Economic Performance and Social Progress. Ec.europa.eu. [Электронный ресурс]. URL: http://ec.europa.eu/environment/beyond_gdp/download/ CMEPSP-final-report.pdf (дата обращения: 21.06.2018).

\section{REFERENCES:}

Doklad o chelovecheskom razvitii 2016. Chelovecheskoe razvitie dlya vsekh i kazhdogo [The human development report 2016. Human development for everyone] (2017). M.: Ves Mir. (in Russian).

Alkamo Dzh. i dr. (2005). Ekosistemy i blagosostoyanie lyudey: ramki otsenki [Ecosystems and human well-being: an assessment framework] Ecosystem assessment on the edge of millenium. (in Russian).

ArtexTrade. Retrieved July 10, 2018, from http://www.artextrade.ru/economy/macro/ chistoe-ekonomicheskoe-blagosostoyanie

Bobylev S.N. (2007). Indikatory ustoychivogo razvitiya: regionalnoe izmerenie. Posobie po regionalnoy ekologicheskoy politike [Indicators of sustainable development: the regional dimension. A manual on regional environmental policy] M.: Akropol, TsEPR. (in Russian).

Pavlova I.A., Gumennikov I.V., Monastyrnyy E.A. (2017). Mezhdunarodnye integralnye indeksy kak sravnitelnye metodiki makrourovnya $\mathrm{v}$ otsenke blagopoluchiya pozhilogo naseleniya [International integrated indices as comparative macro-level methods in the assessment of the well-being of the elderly population]. Vestnik nauki Sibiri. (1(24)). (in Russian).

Shmatova Yu.E., Morev M.V. (2015). Izmerenie urovnya schastia: literaturnyy obzor rossiyskikh i zarubezhnyh issledovaniy [Assessing the Level of Happiness: a Review of Russian and Foreign Research]. Economic and Social Changes: Facts, Trends, Forecast. (3(39)). (in Russian). doi: 10.15838/esc/2015.3.39.11 .

Stiglitz Joseph E., Sen Amartya, Fitoussi Jean-Paul. Report by the Commission on the Measurement of Economic Performance and Social ProgressEc.europa.eu. Retrieved June 21, 2018, from http://ec.europa.eu/environment/beyond_gdp/download/ CMEPSP-final-report.pdf 